\title{
A comparative study on the effect of radial keratotomy in patients who live at sea level and high altitude
}

\begin{abstract}
Purpose To compare the refractive and keratometric results of matched pairs of patients who underwent radial keratotomy (RK) at sea level and high altitude. Methods The results of $\mathbf{3 0}$ eyes that underwent RK procedures in two clinical centres at different altitude were analysed. One centre was at sea level (Istanbul) and the other at an altitude of $1720 \mathrm{~m}$ (Van). The patients in the two centres were matched regarding gender, age, degree of myopia, number of incisions and optic zone size. There were 15 eyes in each group. All operations were performed with a diamond blade using a Russian technique by the same surgeon. Results The mean pre-operative spherical equivalent cycloplegic refractions (SECR) were $-6.33 \pm 1.15 \mathrm{D}$ and $-6.32 \pm 1.01 \mathrm{D}$ in the Istanbul and Van groups, respectively $(p=0.96)$. The mean post-operative SECRs were $-1.93 \pm 1.03 \mathrm{D}$ and $-0.28 \pm 0.57 \mathrm{D}$ in the Istanbul and Van groups, respectively $(p<0.001)$. The mean SECR changes were $4.40 \pm 0.92 \mathrm{D}$ and $6.03 \pm 1.13 \mathrm{D}$ in subjects who had undergone RK at sea level and at $1720 \mathrm{~m}$, respectively $(p<0.001)$.

Conclusion These results show that a higher myopic correction can be provided in patients who undergo RK at high altitude compared with those operated on at sea level. The RK nomograms used by refractive surgeons performing RK surgery at high altitude may need to be redesigned in the light of future studies with long-term follow-up.
\end{abstract}

Key words Altitude, Barometric pressure, Hypoxia, Myopia, Radial keratotomy

Radial keratotomy (RK) is a commonly performed procedure for the correction of myopia. Technological advances in instrumentation, the use of corneal topography, as well as a greater understanding of corneal biomechanics, including the influences of patient age, wound morphology and wound
ADNAN ÇINAL, TEKIN YAŞAR AHMET DEMIROK, ŞABAN ŞIMŞEK, Ö. FARUK YILMAZ

healing, have all contributed to the improved level of safety, efficacy and predictability. ${ }^{1-4}$ Predictability is the most important problem in RK. Most surgeons believe that the efficacy of RK is related to incision number, incision depth, corneal refractive power, optic zone $(\mathrm{OZ})$ size, age, gender, intraocular pressure (IOP), tissue factors affecting wound healing, and some other unknown factors. ${ }^{1,2,4-7}$ However, there is no general agreement regarding these criteria in RK formulation.

Altitude, which is a new factor affecting RK results, should also be considered as a criterion for predictability of RK procedures. Five reports that have described hyperopic shifts in refractive error in patients who had RK after a short exposure to high altitude have involved very small numbers of subjects. ${ }^{8-12}$ We do not know at what altitude such hypoxic changes first occur, nor whether they are stable or continue to progress with more extended exposure at a given altitude. Previous studies have investigated the RK results of the patients who lived at sea level and then travelled to high altitudes. We recently reported the first study dealing with the RK results of patients who lived at high altitude and were adapted to decreased barometric pressure and oxygen concentration, compared with unmatched cases. $^{13}$

Since that time we have expanded our database. In this article we compare the refractive and keratometric results of matched pairs of patients who underwent RK at sea level or high altitude, and discuss the effects of altitude on RK.

\section{Materials and methods}

Two hundred and twenty-six eyes undergoing RK in two different clinical centres between May 1996 and September 1997 were analysed retrospectively. One centre was at sea level (Istanbul) and the other at an altitude of $1720 \mathrm{~m}$ (Van). The barometric pressure was $760 \mathrm{mmHg}$ and oxygen pressure averaged $160 \mathrm{mmHg}$ in Istanbul; the equivalent values in Van were

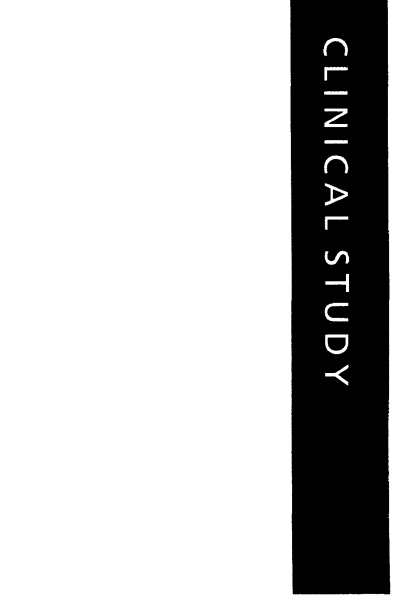

A. Çınal

T. Yaşar

A. Demirok

Ş. Şimşek

Ö.F. Yılmaz

Yüzüncü Yıl University

Medical Faculty

Department of

Ophthalmology

Van, Turkey

Dr Adnan Çınal

Y.Y.Ü. Tıp Fakültesi

Göz Hast. Anabilim Dalı

Van, Turkey

Tel: +90 (432) 2166563

Fax: +90 (432) 2166563

Presented as a poster presentation at the Xlth Congress of the European Society of Ophthalmology, Hungary, Budapest,

1-5 June 1997

Received: 28 April 1998 Accepted in revised form: 25 January 1999 
$587 \mathrm{mmHg}$ and $123 \mathrm{mmHg}$. Barometric pressure and oxygen pressure were thus $20 \%$ lower in Van than in Istanbul. The two centres had almost the same climatic conditions.

Fifteen eyes in the Istanbul group were matched with 15 in the Van group regarding gender, age, degree of myopia, number of incisions, and OZ size. One hundred and ninety-six eyes were excluded from the study. The exclusion criteria were: (1) any systemic illness, (2) taking any medication, (3) history of travel within 1 month before the operation and post-operative period, (4) any complications such as micro- and macro-perforation in the per-operative and post-operative period and (5) inability to match the eye with one in the other group. There were 6 women and 5 men in the Istanbul group, and 4 women and 6 men in the Van group; all patients were white and Turks. Each group had 15 eyes. All operations were performed with a diamond blade using a Russian technique by the same surgeon (O.F.Y.) in two different clinical centres.

All subjects were informed about the procedure in detail beforehand, the possible complications and expectations they should have.

Manifest and cycloplegic refraction (cycloplegic refractions were performed 20-30 min after instilling two drops of tropicamide $1 \% 5 \mathrm{~min}$ apart), keratometry (Javal-Schiötz Ophthalmometer, Haag-Streit), computed video keratography (Eyesys Photokeratoscope-16 Corneal analysis system V2.1), ultrasonic biometry, applanation tonometry (Goldmann applanation tonometer) and central-peripheral corneal pachymetry (BVI pachymeter echograph model: pocket BV International) were determined in all subjects. Determination of OZ size and incision number were based on many factors such as the degree of desired correction, age, gender, refraction and keratometric values, and the prior experience of the surgeon. Because some revisions were made to the nomograms used according to the experience of the surgeon, we can not give the unique nomogram used in the study. However, as shown in Table 1 and explained in the paragraph below, the same nomograms were used by the same surgeon for both eyes of a matched pair. Data for all cases are given in Table 1.

Surgery was performed under topical anaesthesia with a coaxial operating microscope. The patient's fellow eye was covered and the patient told simply to 'look at the dot in the centre of the microscope lens' with the uncovered eye. A double-pronged fixation forceps was used because of the difficulty for patients to fixate on the microscope light. The optical centre marker was then pressed on the cornea in the centre of the pupil. A marker with ridges imprinted the location of the incisions in the epithelium as it was depressed on the cornea. A Russian diamond blade was extended to $100 \%$ of the thinnest $3 \mathrm{~mm}$ paracentral corneal measurement using a calibrating scale under the operating microscope. Russian-technique incisions were initiated by plunging

Table 1. Data of all cases

\begin{tabular}{|c|c|c|c|c|c|c|}
\hline \multirow[b]{2}{*}{ Groups } & \multirow{2}{*}{$\begin{array}{l}\text { Sex/Age } \\
\text { (years) }\end{array}$} & \multicolumn{2}{|c|}{ Refractions (dioptre) } & \multicolumn{2}{|c|}{ Keratometry values (dioptre) } & \multirow{2}{*}{$\begin{array}{c}\text { Incision number/ } \\
\text { OZ size }(\mathrm{mm})\end{array}$} \\
\hline & & Pre-operative & Post-operative & Pre-operative & Post-operative & \\
\hline I & $\mathrm{M} / 25$ & -7.50 & -3.50 & 42.50 & 39.00 & $12 / 3$ \\
\hline $\mathrm{V}$ & $\mathrm{M} / 26$ & -7.50 & -0.75 & 40.75 & 33.75 & $12 / 3$ \\
\hline I & $\mathrm{F} / 36$ & -7.50 & -2.00 & 41.75 & 34.00 & $10 / 3$ \\
\hline I & $\mathrm{F} / 41$ & -7.25 & -2.75 & 46.25 & 42.50 & $10 / 3$ \\
\hline $\mathrm{V}$ & $\mathrm{F} / 38$ & -7.50 & -1.00 & 46.00 & 42.50 & $10 / 3$ \\
\hline I & $\mathrm{M} / 32$ & -7.25 & -2.60 & 43.50 & 37.25 & $12 / 3$ \\
\hline V & $\mathrm{M} / 33$ & -7.50 & +0.75 & 43.25 & 37.25 & $12 / 3$ \\
\hline I & $\mathrm{F} / 25$ & -7.00 & -2.75 & 46.75 & 38.50 & $10 / 3$ \\
\hline V & $F / 24$ & -7.25 & +0.50 & 43.00 & 41.00 & $10 / 3$ \\
\hline I & $\mathrm{F} / 24$ & -7.25 & -1.75 & 46.00 & 39.75 & $10 / 3$ \\
\hline I & $\mathrm{F} / 25$ & -7.00 & -1.50 & 43.50 & 37.25 & $10 / 3$ \\
\hline V & $\mathrm{F} / 24$ & -7.00 & -0.50 & 42.50 & 36.75 & $10 / 3$ \\
\hline I & $\mathrm{M} / 28$ & -7.00 & -2.00 & 44.50 & 41.50 & $12 / 3$ \\
\hline V & M/31 & -7.00 & -0.50 & 41.25 & 37.25 & $12 / 3$ \\
\hline I & $\mathrm{M} / 22$ & -6.50 & -2.00 & 46.25 & 42.75 & $12 / 3$ \\
\hline V & $\mathrm{M} / 21$ & -7.00 & -0.50 & 41.25 & 37.25 & $12 / 3$ \\
\hline I & $\mathrm{F} / 31$ & -6.25 & -2.00 & 46.50 & 40.00 & $12 / 3$ \\
\hline V & $F / 35$ & -6.50 & -0.50 & 41.50 & 36.50 & $12 / 3$ \\
\hline I & $\mathrm{M} / 25$ & -6.00 & -2.50 & 42.50 & 38.50 & $12 / 3$ \\
\hline V & $\mathrm{M} / 25$ & -6.00 & -0.50 & 42.50 & 37.25 & $12 / 3$ \\
\hline V & $\mathrm{M} / 26$ & -6.00 & -0.25 & 42.50 & 36.75 & $12 / 3$ \\
\hline I & $\mathrm{F} / 20$ & -5.00 & -2.75 & 43.75 & 40.25 & $10 / 3$ \\
\hline V & $\mathrm{F} / 19$ & -5.00 & -0.25 & 44.25 & 39.00 & $10 / 3$ \\
\hline I & $\mathrm{M} / 22$ & -4.50 & +0.25 & 45.00 & 42.50 & $10 / 3.2$ \\
\hline $\mathrm{V}$ & $\mathrm{M} / 25$ & -5.00 & +1.00 & 41.25 & 36.00 & $10 / 3.2$ \\
\hline $\mathrm{V}$ & $\mathrm{M} / 24$ & -5.00 & -0.75 & 42.75 & 37.25 & $10 / 3.2$ \\
\hline I & $\mathrm{M} / 22$ & -4.50 & +0.25 & 44.75 & 42.00 & $10 / 3.2$ \\
\hline V & $\mathrm{M} / 24$ & -5.00 & -0.50 & 43.00 & 36.75 & $10 / 3.2$ \\
\hline I & $\mathrm{F} / 20$ & -4.50 & -1.50 & 43.50 & 39.25 & $10 / 3$ \\
\hline $\mathrm{V}$ & $\mathrm{F} / 19$ & -5.50 & -0.50 & 43.75 & 39.00 & $10 / 3$ \\
\hline
\end{tabular}

I, Istanbul group; V, Van group; OZ, optic zone. 
the blade into the stroma and extended in centripetal fashion no closer than $1 \mathrm{~mm}$ from the corneoscleral limbus. The surgeon made 10 or 12 radial incisions from the limbus to the OZ. Blood and foreign material were irrigated from the wound using a fine blunt cannula and irrigating parallel to the corneal surface. Then the eye was instilled with $0.3 \%$ tobramycin sulphate and covered with a patch for $24 \mathrm{~h}$. Post-operative medical therapy included a 5-day regimen of topical steroid ( $1 \%$ prednisolone acetate), prophylactic antibiotics $(0.3 \%$ tobramycin sulphate) and artificial tears instilled four times a day, followed by 3 days of twice-daily instillation. When the spherical equivalent cycloplegic refraction (SECR) was greater than $+1.00 \mathrm{D}$ within the first post-operative week, steroid was discontinued.

The surgeon examined the patients on the first postoperative day, and then at 3 days, 10 days, 1 month, 3 months and 6 months after the operation. We evaluated the last visit values of the patients. All examinations were performed between 0900 and 1200 hours to avoid the effects of diurnal changes on refraction and IOP. All refractive results are listed using the spherical equivalent. The mean post-operative follow-up time was $5.02 \pm 0.14$ and $4.21 \pm 0.25$ months in the Istanbul and Van groups, respectively.

Comparisons were made using a paired-samples Student's $t$-test and the Wilcoxon signed ranks test $(p<0.05$ significant).

\section{Results}

The mean age was $26.53 \pm 6.05$ years (range 19-41 years) and $26.26 \pm 5.59$ years (range 19-38 years) in the Istanbul and Van groups, respectively $(p=0.90)$. The subjects had pre-operative refractive errors ranging from -4.50 to $-7.50 \mathrm{D}(-6.33 \pm 1.15 \mathrm{D})$ and from -5.00 to $-7.50 \mathrm{D}$ $(-6.32 \pm 1.01 \mathrm{D})$, respectively $(p=0.96)$ (Fig. 1$)$. Their pre-operative keratometric values ranged from 41.75 to
$46.75 \mathrm{D}(44.47 \pm 1.62 \mathrm{D})$ and from 40.75 to $46.00 \mathrm{D}$ $(42.63 \pm 1.37 \mathrm{D})$ in the Istanbul and Van groups, respectively ( $p=0.002$ ) (Fig. 2 ).

The mean post-operative SECRs for the Istanbul and Van groups were $-1.93 \pm 1.03$ and $-0.28 \pm 0.57 \mathrm{D}$, respectively. There was a significant difference between the mean post-operative SECRs $(p<0.001)$ in the two groups (Fig. 1).

The mean post-operative keratometric values were $39.66 \pm 2.42$ and $37.58 \pm 2.10 \mathrm{D}$ in the Istanbul and Van groups, respectively. The difference between the mean post-operative keratometric values was statistically significant ( $p=0.018$ ) (Fig. 2).

The mean refractive and keratometric changes implied the difference between pre-operative and postoperative values. Thus the mean changes in SECR were $4.40 \pm 0.92 \mathrm{D}(69.5 \%$ decrease relative to the preoperative mean SECR) and $6.03 \pm 1.13 \mathrm{D}(95.4 \%$ decrease relative to the pre-operative mean SECR), and in keratometry $4.80 \pm 1.88$ (10.8\% decrease relative to the pre-operative mean $\mathrm{K}$ value) and $4.98 \pm 1.23 \mathrm{D}(11.7 \%$ decrease relative to the pre-operative mean $\mathrm{K}$ value) in the Istanbul and Van groups, respectively. There was a $1.63 \pm 1.06 \mathrm{D}$ difference between the mean refractive changes of the two groups. The amounts of correction per $1 \mathrm{D}$ myopia were $0.69 \mathrm{D}$ and $0.95 \mathrm{D}$ after RK surgery in the Istanbul and Van groups, respectively. The difference between the mean refraction changes in the two groups was statistically significant $(p<0.001)$, whereas the difference between the mean keratometry changes was insignificant ( $p=0.75$ ) (Fig. 3).

Both the Istanbul and Van groups were divided into two subgroups according to the pre-operative SECR: from -4.50 to $-6.00 \mathrm{D}\left(\mathrm{I}_{\mathrm{A}}\right.$ (5 eyes) and $\mathrm{V}_{\mathrm{A}}$ ( 7 eyes) groups) and $-6.00 \mathrm{D}$ and over $\left(\mathrm{I}_{\mathrm{B}}(10\right.$ eyes $)$ and $\mathrm{V}_{\mathrm{B}}(8$ eyes) groups). Pre-operative SECR and the mean change were $-4.9 \pm 0.65 \mathrm{D}$ and $3.65 \pm 1.09 \mathrm{D}(74 \%$ of preoperative $\mathrm{SECR}$ ) in the $\mathrm{I}_{\mathrm{A}}$ group. The amount of correction per $1 \mathrm{D}$ myopia was $0.74 \mathrm{D}$ in this group. Preoperative SECR and the mean correction were

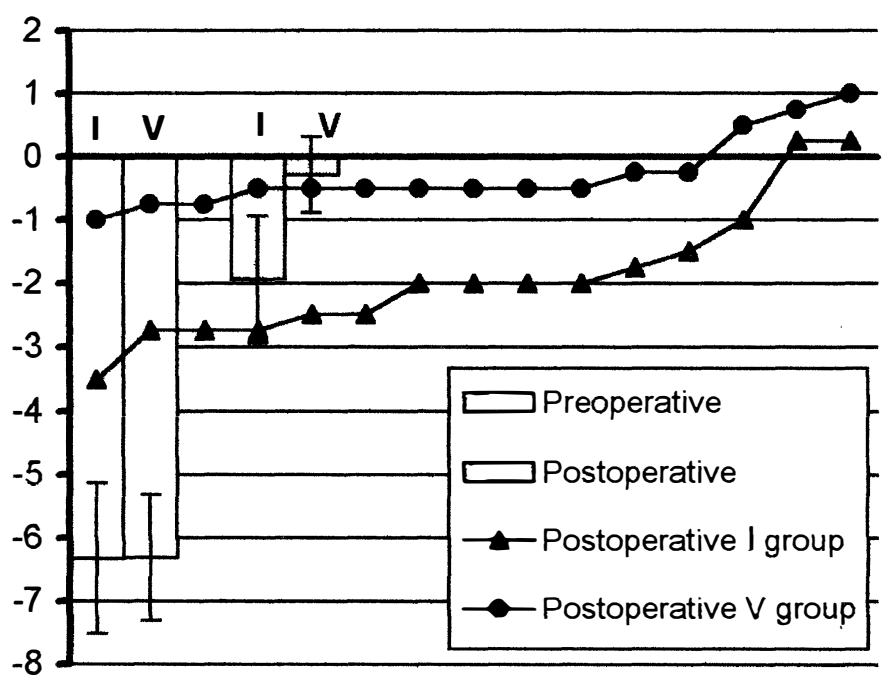

Fig. 1. Pre-operative and post-operative mean spherical equivalent cycloplegic refraction (SECR) values $\pm S D$ (in dioptres) in the Istanbul (I) and Van (V) groups. 


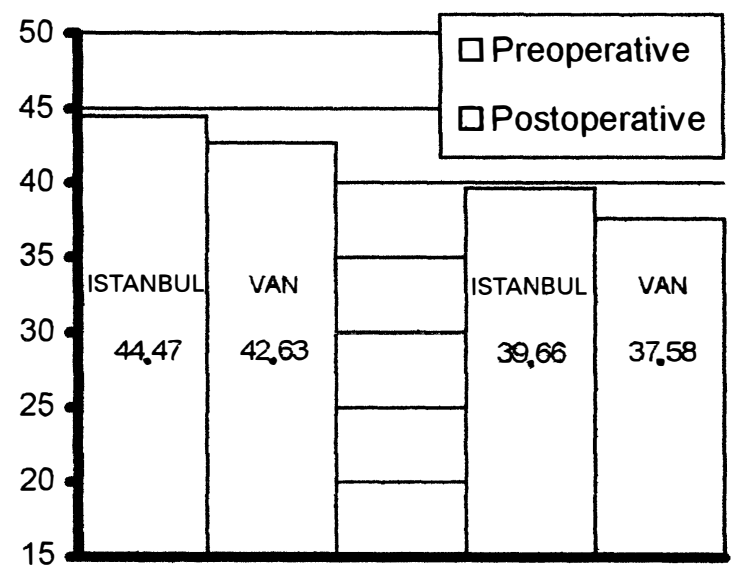

Fig. 2. Pre-operative and post-operative mean keratometry values (in dioptres) in the Istanbul and Van groups.

$-7.07 \pm 0.35 \mathrm{D}$ and $4.77 \pm 0.57 \mathrm{D}$ in the $\mathrm{I}_{\mathrm{B}}$ group. The amount of correction per $1 \mathrm{D}$ myopia was $0.67 \mathrm{D}(67 \%$ of pre-operative SECR) in this group. Pre-operative SECR and the mean change were $-5.35 \pm 0.47 \mathrm{D}$ and $5.11 \pm 0.66 \mathrm{D}$ ( $96 \%$ of pre-operative $\mathrm{SECR})$ in the $\mathrm{V}_{\mathrm{A}}$ group. The amount of correction per $1 \mathrm{D}$ myopia was $0.96 \mathrm{D}$ in this group. Pre-operative SECR and the mean change were $-7.12 \pm 0.42 \mathrm{D}$ and $6.78 \pm 0.81 \mathrm{D}(95 \%$ of pre-operative SECR) in the $V_{B}$ group. The amount of correction per $1 \mathrm{D}$ myopia was $0.95 \mathrm{D}$ in this group.

Pre-operative and post-operative mean pachymetry of the Van group were $530.67 \pm 40.57 \mu \mathrm{m}$ and

$541.00 \pm 30.85 \mu \mathrm{m}$, respectively. The difference between the mean pre-operative and post-operative pachymetry values was $10.33 \pm 12.05 \mu \mathrm{m}$, which was statistically significant $(p=0.005)$. Pre-operative and post-operative mean pachymetry of the Istanbul group were $537.73 \pm 21.25 \mu \mathrm{m}$ and $544.13 \pm 24.86 \mu \mathrm{m}$, respectively. The difference between the mean pre-operative and postoperative pachymetry values was $6.27 \pm 10.02 \mu \mathrm{m}$, which was statistically significant $(p=0.029)$. There was no statistically significant difference between the mean change in the pachymetry values of the Van and Istanbul groups $(p=0.32)$.

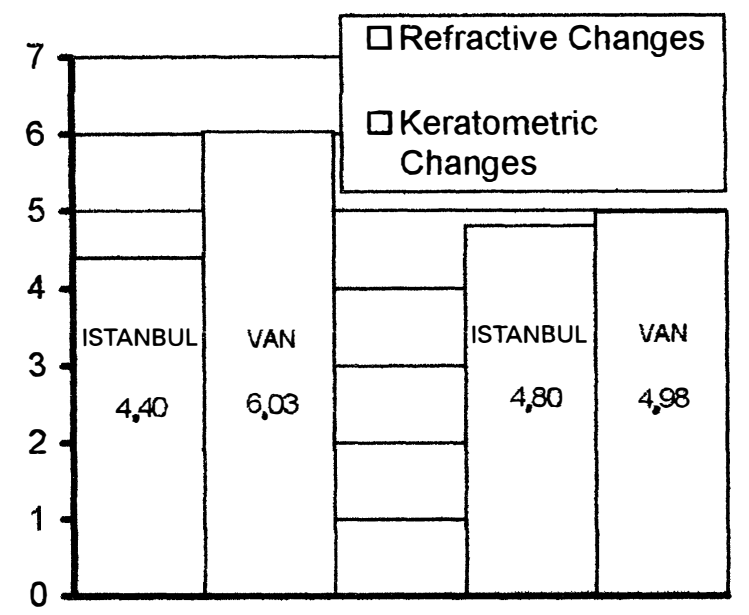

Fig. 3. Refractive and keratometric changes (in dioptres) in the Istanbul and Van groups.
Pre-operative and post-operative mean IOPs of the Van group were $14.45 \pm 2.56 \mathrm{mmHg}$ and $13.75 \pm 1.71 \mathrm{mmHg}$, respectively. The difference between the mean pre-operative and post-operative IOPs was $-0.43 \pm 1.78 \mathrm{mmHg}$, which was statistically insignificant $(p=0.075)$. Pre-operative and post-operative mean IOPs of the Istanbul group were $15.78 \pm 3.02$ $\mathrm{mmHg}$ and $15.23 \pm 2.35 \mathrm{mmHg}$, respectively. The difference between the mean pre-operative and postoperative IOPs was $-0.52 \pm 1.73 \mathrm{mmHg}$, which was statistically insignificant $(p=0.25)$. There was no statistically significant difference between the mean change in the IOP values of the Van and Istanbul groups $(p=0.89)$.

\section{Discussion}

Although many reports have described the postoperative stability of RK, no comprehensive, matchedcases and long-term study has documented postoperative refractive changes with respect to altitude. Previous studies have involved only one measurement at each altitude, mainly at sea level, on a relatively small number of subjects. ${ }^{10-12}$ We aimed to compare the results of matched subjects who had RK at either $1720 \mathrm{~m}$ or sea level, and thus to find out the effect of altitude on the RK results.

Hyperopic shift and corneal flattening with exposure to increasing altitude have been described in subjects who have had RK. ${ }^{10,12}$ The magnitude of the hyperopic shift was progressive with increasing altitude, but whether the shift is progressive at the same altitude over time is unknown. ${ }^{8-12}$ Synder et al. ${ }^{8}$ reported a $1.75 \mathrm{D}$ hyperopic shift and $1.50 \mathrm{D}$ corneal flattening in a subject who travelled from sea level to an altitude of 9000 feet $(2770 \mathrm{~m})$. They suggested that these changes might have been caused by the direct effect of decreased barometric pressure. White and Mader ${ }^{9}$ documented a $1.00 \mathrm{D}$ hyperopic shift and 1.00 D corneal flattening in both eyes of one subject who travelled from sea level to an altitude of 10000 feet $(3100 \mathrm{~m})$. The refractions returned to normal when the patient moved back to sea level. The authors hypothesised that hyperopic shift resulted from a metabolic process caused by the effect of corneal hypoxia on the area of the RK incisions. ${ }^{10}$ They defined it as 'hypoxic corneal expansion'. We found a $1.63 \pm 1.06 \mathrm{D}$ difference in the mean refractive change between the sea level and $1720 \mathrm{~m}$ groups at the third post-operative month. These results obtained at $1720 \mathrm{~m}$ appear much higher than in previous studies. This may result from our using 3-3.2 mm OZ size and 10-12 incisions.

It is well documented that ocular oxygen tension decreases with increasing altitude, and a normal cornea exposed to zero oxygen concentration will swell approximately $7 \%$ per hour. ${ }^{14,15}$ Small increases in corneal thickness occur in normal corneas during sleep and as a result of local hypoxia brought about by contact lens use. ${ }^{12}$ Barometric pressure and oxygen pressure were $20 \%$ lower in Van than in Istanbul. We found statistically significant changes in pachymetry between 
the pre-operative and post-operative periods in the two groups. The increase in corneal thickness was more prominent in the Van group than the Istanbul group, but no statistically significant difference in the changes in pachymetry values between the two groups were observed between the pre-operative and post-operative periods.

$\mathrm{Ng}$ et al. ${ }^{11}$ found a statistically significant difference in mean central pachymetry readings between control and RK eyes for measurements at $6 \mathrm{~h}$ and $8 \mathrm{~h}$ at a simulated altitude of 12000 feet $(3700 \mathrm{~m}) .{ }^{11}$ Mader et al. ${ }^{12}$ found a statistically significant increase in central corneal pachymetry after RK at high altitude, and at the postaltitude sea level examination the central corneal thickening had resolved. ${ }^{12}$

In our study, no significant changes in IOP were observed between the pre-operative and post-operative periods in the two groups. Mader et al. ${ }^{12}$ studied at sea level, 6000 feet $(1850 \mathrm{~m})$ and 14100 feet $(4350 \mathrm{~m})$ the same patient who had undergone RK; no significant changes in IOP were observed at any altitude.

The cornea becomes more sensitive to IOP and barometric pressure alterations after RK because the greater the number of RK incisions, the greater the circumferential elasticity. ${ }^{11,16,17}$ It is possible that the weakened cornea in RK eyes exposed to decreased barometric pressure might bow forward with the effect on IOP. On the other hand, IOP remained unchanged during exposure to high altitude or a simulated altitude chamber. ${ }^{11,12,15}$ The decrease in barometric pressure at high altitude is a common physical rule. In this case, it is possible that the weakened cornea in RK eyes exposed to decreased barometric pressure is able to bow forward with the effect on IOP and then to undergo central corneal flattening. We believe that this mechanism was also effective at high altitude in our cases.

Ultraviolet radiation intensity at high altitude is higher than at sea level. Also people who live at high altitude may exhibit some unknown metabolic alterations and changes in wound-healing responses. These factors may affect corneal wound healing and RK results at high altitude.

It is not known at what altitude the hyperopic shift starts. Nonetheless, our study showed the presence of a hyperopic shift, in other words a comparatively high refraction increase relative to sea level, at $1720 \mathrm{~m}$. We do not know yet whether, after complete healing at high altitude, the newly shaped cornea will deteriorate and considerable regression will occur on a patient's return to sea level. However, refractive changes are seen in patients who underwent RK at sea level and simulated high altitude in the first post-operative year. ${ }^{11}$ This implies that, in patients who undergo RK at high altitude, some refractive changes may occur when they travel to sea level.

In our study the groups had a significant difference between pre-operative keratometry values. On the other hand, it has been reported previously that the preoperative keratometry value is not an important factor in RK predictability. ${ }^{18,19}$
Differences in the keratometry values between the pre-operative and post-operative periods in the two groups were statistically significant. But keratometric changes were insignificant between the Istanbul and Van groups. In this study we focused on the refractive results because it has been shown that post-RK keratometry readings are not meaningful because of the aspherical shape of the cornea after RK surgery. ${ }^{18,19}$

We found that there was a significant difference between the Istanbul and Van groups (more than $50 \%$ of correction of Istanbul in Van group) in respect of the amount of myopia correction. The myopic correction ratio was $74 \%$ of pre-operative myopia in the $I_{A}$ subgroup while it was $67 \%$ in the $I_{B}$ subgroup. The equivalent ratios were $96 \%$ and $95 \%$ in the $V_{A}$ and $V_{B}$ subgroups, respectively. These results suggested that at sea level it was more difficult to achieve emmetropia in eyes with over $-6.00 \mathrm{D}$ myopia pre-operatively than with $-6.00 \mathrm{D}$ and under. For this reason, many authors have preferred not to carry out a RK procedure in eyes with over $-6.00 \mathrm{D}$ myopia pre-operatively. In contrast the same ratio of emmetropia was achieved in eyes with all degrees of myopia at high altitude.

Our results show that RK is more effective in patients who are natives of high altitude than in those who live at sea level, and this feature continues until the third postoperative month. We can not interpret which mechanisms (hypoxia, barometric pressure, UV radiation, and other unknown factors) affect these results, because the aim of the study was only to determine the effect of altitude on RK results.

Although the number of our cases was not sufficient to determine definitive results, we believe that for the confirmation of these results more detailed and comprehensive studies with higher numbers of cases are needed. In conclusion, refractive surgeons may be obliged to redesign their nomograms with regard to oxygen and barometric pressure in the light of future studies with long-term follow-up.

\section{References}

1. Sanders DR, Deitz M, Gollogher D. Factors affecting predictability of radial keratotomy. Ophthalmology 1985;92:1237-43.

2. Merlin U, Bordin P, Rimondi AP. Factors that affect keratotomy depth. Refract Corneal Surg 1991;7:356-9.

3. Waring GO. Atlas of surgical techniques of radial keratotomy. In: Waring GO, editor. Refractive keratotomy for myopia and astigmatism. St Louis: Mosby-Year Book, 1992:507-639.

4. Deitz MR, Sanders DR, Raanan MG, De Luca M. Long term (5- to 12-year) follow-up of metal blade radial keratotomy procedures. Arch Ophthalmol 1994;112:614-20.

5. Özçetin H. Radial keratotomi. T Oft Gaz 1988;18:240-50.

6. Yilmaz ÖF. Radial keratotomide metodlar ve ekipmanlar. Kış Simp, Uludağ, Bursa 1990;133-6.

7. Kaya V, Kevser MA, Akaydin Ö, Kadıŏlu E, Yılmaz ÖF. Radial keratotomide üç yıllık deneyimimiz, TOD XXVII. Ulusal Kongre Bülteni, Yeniyol matb, Marmaris, 1993;1:417-21. 
8. Synder RP, Klein P, Solomon J. The possible effect of barometric pressure on the corneas of an RK patient: a case report. Int Contact Lens Clin 1988;15:130-2.

9. White LJ, Mader TH. Refractive changes with increasing altitude after radial keratotomy [letter]. Am J Ophthalmol 1993;115:821-3.

10. Mader TH, White LJ. Refractive changes at extreme altitude following radial keratotomy. Am J Ophthalmol 1995;119:733-7.

11. Ng JD, White LJ, Parmley VC, Hubickey W, Carter J. Effects of simulated high altitude on patients who have had radial keratotomy. Ophthalmology 1996;103:452-7.

12. Mader TH, Blanton CL, Gilbert BN, Kubis KC, et al. Refractive changes during 72-hour exposure to high altitude after refractive surgery. Ophthalmology 1996;103:1188-95.

13. Şimşek Ş, Demirok A, Çinal A, Yaşar T, Yilmaz ÖF. The effect of altitude on radial keratotomy. Jpn J Ophthalmol 1998;42:119-23.
14. Mader TH, Friedl KE, Mohr LC, Berhard WN. Conjunctival oxygen tension at high altitude. Aviat Space Environ Med $1987 ; 58: 76-9$.

15. Polse KA, Mandell RB. Critical oxygen tension at the corneal surface. Arch Ophthalmol 1970;84:505-8.

16. Kohlhaas M, Bohm A, Lerche RC, Hjortdal JO, Ehlers N, Draeger J. Biomechanische Untersuchung der Hornhautstabilität nach radiarer Keratotomie. Klin Monatsbl Augenheilkd 1996;208:285-7.

17. Hjortdal JO, Bohm A, Kohlhaas M, Olsen H, Lerche R, Ehlers $\mathrm{N}$, et al. Mechanical stability of the cornea after radial keratotomy and photorefractive keratectomy. J Refract Surg 1996;12:459-66.

18. Sawelson H, Marks RG. Five-year results of radial keratotomy. Refract Corneal Surg 1989;5:8-20.

19. Arrowsmith PN, Marks RG. Visual, refractive, and keratometric results of radial keratotomy: five-year follow-up [see comment]. Arch Ophthalmol 1989;107:506-11. 